Research Paper

\title{
Morphological changes and growth of filamentous fungi in the presence of high concentrations of PAHs
}

\author{
German Zafra, Angel E. Absalón, Diana V. Cortés-Espinosa \\ Instituto Politécnico Nacional, Centro de Investigación en Biotecnología Aplicada, Tlaxcala, México
}

Submitted: July 10, 2014; Approved: December 28, 2014.

\begin{abstract}
In this study, we evaluated the effect of low and high molecular weight polycyclic aromatic hydrocarbons (PAHs), i.e., Phenanthrene, Pyrene and Benzo[a]pyrene, on the radial growth and morphology of the PAH-degrading fungal strains Aspergillus nomius $\mathrm{H} 7$ and Trichoderma asperellum $\mathrm{H} 15$. The presence of PAHs in solid medium produced significant detrimental effects on the radial growth of $A$. nomius $\mathrm{H} 7$ at 4,000 and $6,000 \mathrm{mg} \mathrm{L}^{-1}$ and changes in mycelium pigmentation, abundance and sporulation ability at $1,000-6,000 \mathrm{mg} \mathrm{L}^{-1}$. In contrast, the radial growth of $T$. asperellum $\mathrm{H} 15$ was not affected at any of the doses tested, although sporulation was observed only up to $4,000 \mathrm{mg} \mathrm{L}^{-1}$ and as with the $\mathrm{H} 7$ strain, some visible changes in sporulation patterns and mycelium pigmentation were observed. Our results suggest that fungal strains exposed to high doses of PAHs significantly vary in their growth rates and sporulation characteristics in response to the physiological and defense mechanisms that affect both pigment production and conidiation processes. This finding is relevant for obtaining a better understanding of fungal adaptation in PAH-polluted environments and for developing and implementing adequate strategies for the remediation of contaminated soils.
\end{abstract}

Key words: polycyclic aromatic hydrocarbons (PAHs), bioremediation, radial growth, sporulation, fungal physiology.

\section{Introduction}

Polycyclic aromatic hydrocarbons (PAHs) are an important group of persistent organic pollutants that are primarily produced as a consequence of thermal decomposition, incomplete combustion and pyrolysis of diverse organic molecules (Mrozik and Piotrowska-Seget, 2010). Due to their physicochemical properties, PAHs are highly hydrophobic compounds that persist in the environment and have potentially cytotoxic, carcinogenic, genotoxic and mutagenic effects on the flora and fauna of impacted habitats, resulting in the absorption and accumulation of several toxic products and active metabolic intermediaries in diverse organisms. Several natural and anthropogenic sources contribute to the release of PAHs into the environment. In particular, petrochemical activities and their related residues exert a strong negative impact on the environment and account for the majority of PAHs and other hydrocarbons released into the soil and bodies of water (Haritash and Kaushik, 2009).

The removal of low (LMW) and high molecular weight (HMW) PAHs from contaminated soils has become an environmental priority (US-EPA, 2008). Although chemical, physicochemical and thermal technologies are available for the remediation of contaminated soils, microbial degradation is considered the main natural degradation mechanism of PAHs. Many bacterial and fungal species are capable of degrading LMW or HMW-PAHs under aerobic or anaerobic conditions (Cerniglia and Sutherland, 2010; Seo et al., 2009), involving the action of mono and dioxygenase, laccase, and peroxidase enzymes among others (Haritash and Kaushik, 2009). Several fungal species possess the ability to degrade PAHs and have the potential to remediate polluted soils; however, one limiting factor in the success of these organisms is their inability to adapt and properly grow on extensively contaminated soils (Tabak et $a l ., 2003)$. The use of native microorganisms that are capa- 
ble of not only degrading PAHs but also having a high level of tolerance to PAHs would reduce the problems associated with adaptation, survival and activity on soils containing high amounts of heavy hydrocarbon fractions (Margesin and Schinner, 2001). However, the effect of aromatic hydrocarbons on the mycelial growth rate and sporulation of tolerant/degrading fungi could be an important factor not only for microbial adaptation but also for adequate cell development and degradation of PAHs. While in the soil, microbial populations are often surrounded by compounds that could serve as a source of carbon and energy, but they are toxic (Ramos et al., 2002). In this sense, the impact of PAHs on fungal populations is a key factor influencing its removal or persistence, particularly in soils with high amounts of toxic compounds. This is particularly important for selecting suitable microorganisms for the bioremediation of soils impacted by PAHs. Thus, the aim of this work was to evaluate the effect of PAHs on the growth of two PAH-degrading fungal strains, to better address the possible inhibitory effects and morphological changes caused in fungi at different PAH doses.

\section{Materials and Methods}

\section{$\mathrm{PAH}$-degrading microorganisms}

Aspergillus nomius $\mathrm{H} 7$ and Trichoderma asperellum H15 were previously isolated from a heavy-crude oil contaminated-soil and are characterized as hydrocarbon-degrading strains, showing increased tolerance levels to 3 (Phenanthrene), 4 (Pyrene) and 5-ring (Benzo[a]pyrene) PAHs (Zafra et al., 2014). Fungi were maintained on potato dextrose agar (PDA) plates at $30^{\circ} \mathrm{C}$. Fresh spores were produced in $250 \mathrm{~mL}$ flasks containing $30 \mathrm{~mL}$ of PDA, inoculated with each of the strains and incubated at $30^{\circ} \mathrm{C}$. After $3 \mathrm{~d}$ of growth, spores were collected with the addition of $20 \mathrm{~mL}$ of $0.1 \%$ tween 80 solution and sterile glass beads.

\section{Effect of PAHs on radial growth}

The effect of analytical grade Phenantrene (Phe), Pyrene (Pyr), and Benzo[a]pyrene (Bap) (Sigma-Aldrich, USA) on the radial growth of $A$. nomius $\mathrm{H} 7$ and $T$. asperellum $\mathrm{H} 15$ was tested by surface plate assays. A $2 \mathrm{~mL}$ mixture of Phe, Pyr and BaP (1:1:1) was dissolved in acetone (Sigma, USA), added to Petri dishes containing $20 \mathrm{~mL}$ of Toyama's Medium (Wunder et al., 1994) and evaporated under sterile conditions to yield final superficial concentrations of 1,000, 2,000, 4,000 and $6,000 \mathrm{mgL}^{-1}$. Plates were centrally inoculated with $1 \times 10^{4}$ spores and incubated at $30{ }^{\circ} \mathrm{C}$ for $7 \mathrm{~d}$. Plates without PAHs that were inoculated with each of the fungal isolates were used as controls. Mycelium radial extension rate measurements $\left(\mathrm{cm} \mathrm{d}^{-1}\right)$ were made every $24 \mathrm{~h}$ by using a vernier digital caliper (Mitotuyo, Kawasaki, Japan).

\section{Effect of PAHs on fungal morphology}

The effect of PAHs on fungal morphology was monitored by direct macromorphological observations of both colony variations and microscopic changes in the mycelium and spores after $10 \mathrm{~d}$ of growth. Stereomicroscopic observations were made by using a Zoom 2000 Stereozoom Microscope (Leica, Wetzlar, Germany). Plate photographs and photomicrographs were taken with a PowerShot SX500 IS digital camera (Canon, New York, USA).

\section{Statistical analysis}

Fungal growth assays were structured by using a $2 \times 5$ factorial design (two strains and five PAH doses). Data from the radial extension rates were analyzed by Analysis of Variance (ANOVA) followed by a multiple comparison test (LSD) with SPSS Statistics Software version 19 (IBM). Differences with a $p$ value $<0.05$ were considered statistically significant. All assays were performed in triplicate.

\section{Results and Discussion}

\section{Effect of PAHs on fungal radial growth}

Because PAH-contaminated soils typically contain complex mixtures of LMW and HMW PAHs, we used high doses of a mixture of 3, 4 and 5-ring PAHs to better address the inhibitory effect caused on fungi in a hypothetical impacted soil. Figure 1 shows the ability of the fungal strains

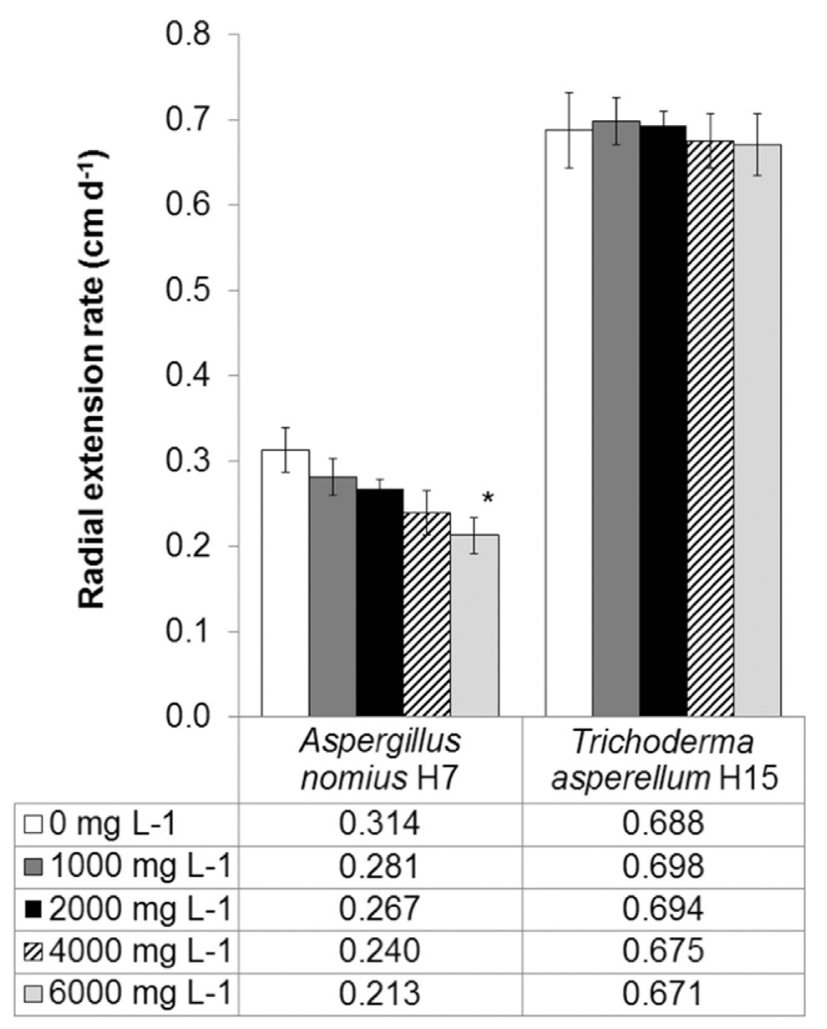

Figure 1 - Radial extension rates of fungal strains in presence of different concentrations of a mixture of Phe, Pyr and BaP. 
to grow in the presence of different doses of PAHs. Compared with control plates, the radial extension rates of $A$. nomius $\mathrm{H} 7$ were not significantly different at 1,000, 2,000 and $4,000 \mathrm{mg} \mathrm{L}^{-1}$, but they were different when growing in the presence of $6,000 \mathrm{mg} \mathrm{L}^{-1}(\mathrm{p}=0.047)$ of the PAH mixture. Although growth inhibition was observed at higher concentrations, the results showed that $A$. nomius spores could successfully germinate, even with $6,000 \mathrm{mg} \mathrm{L}^{-1}$ of PAHs in the medium, and could reach comparable extension rates at intermediate doses. The $\mathrm{H} 7$ strain was isolated from a highly hydrocarbon-polluted soil and previously showed the ability to grow with the same mixture of PAHs as their sole carbon source (Zafra et al., 2014), features that could confer a great adaptive advantage in PAH-contaminated soils (Hinga and Batchellor, 2005). In contrast, there were no apparent detrimental effects of PAHs on the radial growth of $T$. asperellum $\mathrm{H} 15$ because the growth rates showed no significant differences between controls without PAHs and the highest concentration tested $\left(6,000 \mathrm{mg} \mathrm{L}^{-1}\right)$. Unlike A. nomius, $T$. asperellum possess a complex enzymatic machinery capable of oxidizing and cleaving aromatic rings, including laccases, peroxidases and dioxygenases, among others (Cerniglia and Sutherland, 2010), which could actively contribute to adaptation and proper growth in the presence of PAHs. Moreover, $T$. asperellum produces a potent lignocellulolytic cocktail that favors the use of alternative carbon sources (including PAHs) (Marx et al., 2013). This is particularly relevant in soil, where a complex mixture of substrates can be found. The observed mycelium radial extension at extremely high concentrations of PAHs and the ability to use PAHs as a sole carbon source are good indications of the presumptive degradative ability of these strains in soils.

\section{Effect of PAHs on mycelium pigmentation}

Previous studies on PAH metabolism indicated that fungal growth could be significantly impaired in the presence of PAHs (Brodkorb and Legge, 1992). Our results showed that fungal exposure to increased doses of PAHs caused drastic changes in the morphology of both strains compared with uncontaminated controls, particularly on $A$. nomius $\mathrm{H} 7$. PAHs produced evident alterations on the mycelium pigmentation of strain $\mathrm{H} 7$, even when growing at the lowest dose (Figure 2). A slight yellow pigmentation was observed at the periphery of the colonies, and this effect was more evident when the contamination levels increased. Conversely, although the radial growth of $T$. asperellum $\mathrm{H} 15$ was not affected at any of the PAH doses, mycelium pigmentation was affected particularly at 6,000 $\mathrm{mg} \mathrm{L}^{-1}$ (Figure 3).

Our findings are in agreement with previous studies describing yellow pigment formation and mycelial changes in ascomycetes grown on hydrocarbons, including Aspergillus versicolor, Aspergillus ochraceous, Aspergillus alliaceous, Aspergillus niger and Aspergillus

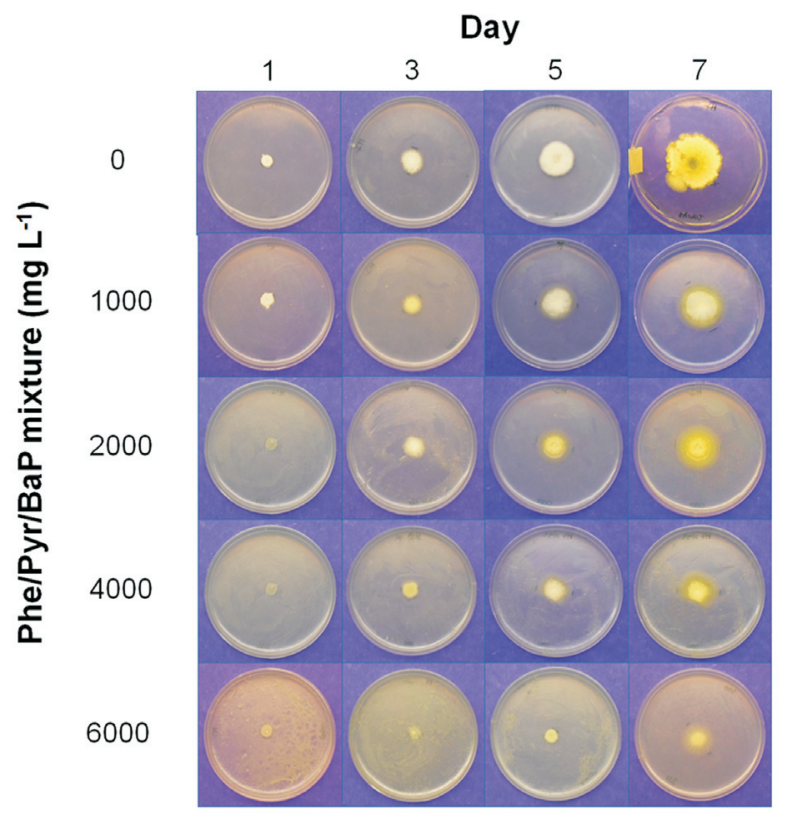

Figure 2 - Effect of different concentrations of Phe, Pyr and $\mathrm{BaP}$ on the radial growth and morphology of Aspergillus nomius $\mathrm{H} 7$.

terreus (Nyns et al., 1968; Zajic and Kuehn, 1962). Similar effects have also been observed in Chrysosporium merdarium and Trichoderma harzianum grown on lubricants, which caused the presence of a thick mycelium and intense mycelial development (Lugauskas et al., 2008). Mycelial yellow pigment production has also been linked to aflatoxin production in $A$. nomius and A. flavus (Abbas et al., 2004; Shier et al., 2005) as a response against

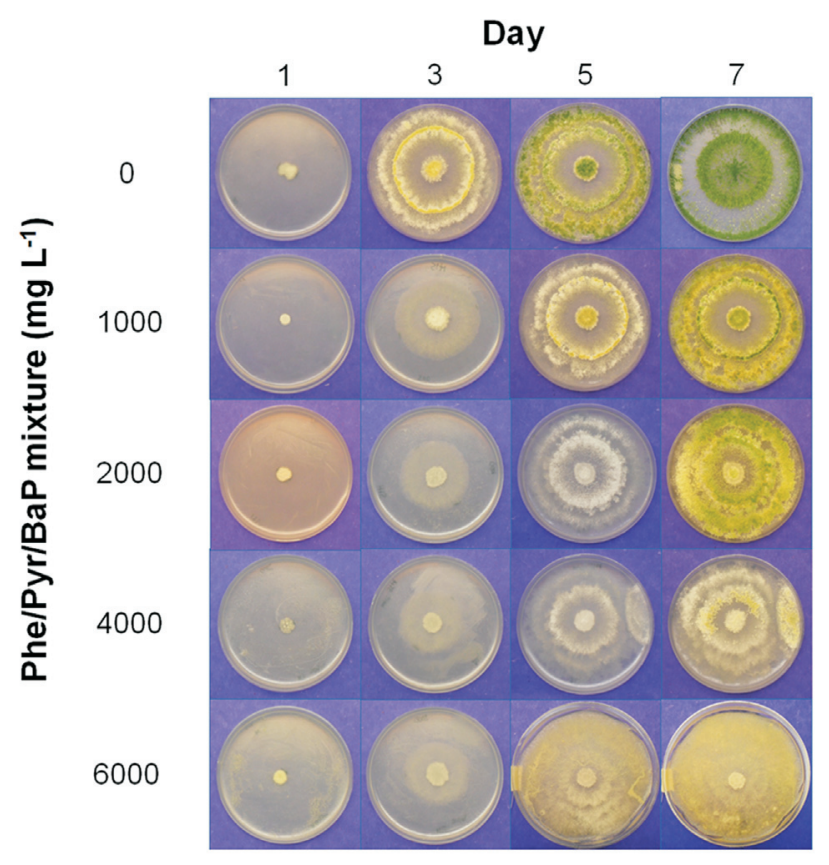

Figure 3 - Effect of different concentrations of Phe, Pyr and BaP on the radial growth and morphology of Trichoderma asperellum H15. 
abiotic stress and limiting growth conditions (Yu et al., 1996). The alterations observed in A. nomius and $T$. asperellum mycelium could therefore be related to an accumulation of hydrocarbons in the central part of the cell membrane, causing dramatic changes in the structure, modifications of membrane fluidity, increased mycelium area and an eventual swelling of the bilayer (Sikkema et al., 1995). Furthermore, hydrocarbon-induced changes could lead to altered membrane function, disrupted cellular homeostasis and impaired energy transduction (Pope et al., 1984).

\section{Effect of PAHs on sporulation}

We found that the presence of PAHs affected the sporulation process in Aspergillus nomius and Trichoderma asperellum to a different extent. Whereas sporulation in A. nomius $\mathrm{H} 7$ was observed from day 5 in control plates, the presence of 1,000 and $2,000 \mathrm{mg} \mathrm{L}^{-1}$ of PAHs retarded the start of sporulation until day 10 , was minimal at $2,000 \mathrm{mg} \mathrm{L}^{-1}$ and was completely absent at 4,000 and 6,000 $\mathrm{mg} \mathrm{L}^{-1}$ (Figure 4). In addition, a gradual change in conidia pigmentation from green to yellow was observed from $1,000 \mathrm{mg} \mathrm{L}^{-1}$ of PAHs and was evident at $2,000 \mathrm{mg} \mathrm{L}^{-1}$ (Figure 4). This effect appeared to be dosedependent and stronger in A. nomius H7. Conversely, $T$.

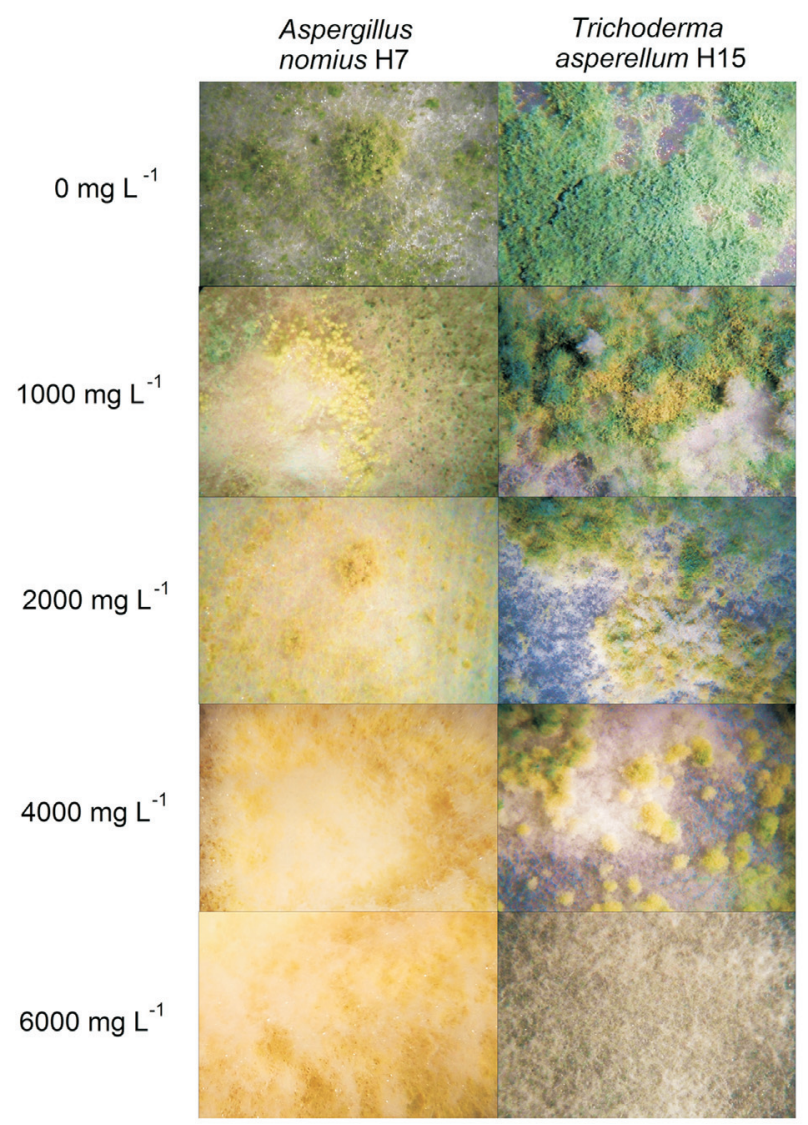

Figure 4 - Stereomicroscopic evaluation of the effect of PAHs on the morphology of fungal strains (magnification 20X). asperellum $\mathrm{H} 15$ showed similar effects in sporulation as those observed in A. nomius H7. However, there was a difference regarding the doses at which sporulation was inhibited, as strain $\mathrm{H} 15$ was able to sporulate even at $4,000 \mathrm{mg} \mathrm{L}^{-1}$ and the conidial pigmentation changes were less pronounced (Figure 4). The impact of the PAH mixture on fungal sporulation was evident, as both strains presented delayed sporulation and showed changes in conidial pigmentation.

Fungal sporulation is a complex process involving the action of many regulatory genes affecting cell specialization and intercellular communication. The central regulatory pathway of conidiation has been described in Aspergillus nidulans, with at least three essential modulatory genes identified (brlA, $a b a \mathrm{~A}$ and $w e t \mathrm{~A})$ (Adams and Yu, 1998). Previous work by our group showed that concentrations as low as $200 \mathrm{mg} \mathrm{L}^{-1}$ of Phe can delay the expression of essential genes in the central regulatory pathway of Aspergillus niger, particularly wetA (Vasquez, 2010). The wetA gene is required in the late phase of conidiation for the synthesis of cell wall layers (Tao and $\mathrm{Yu}, 2011)$. Mutants lacking this gene produce normal conidiophores, but the conidia never become pigmented and autolyse (Sewall et al., 1990). Furthermore, wetA orthologues have been identified in several Trichoderma species as key genes in the conidiation process (Carreras-Villasenor et al., 2012). Thus, it is likely that a $\mathrm{PAH}$-induced delay in the expression of central genes involved in conidiation may be responsible, at least in part, for the observed alterations in delayed sporulation and the changes in pigmentation in both strains, particularly $A$. nomius.

\section{Conclusions}

Our data suggest that fungal strains exposed to high doses of PAHs significantly vary in their growth rate and sporulation characteristics due to alterations in cell membrane structure and the partial inhibition of the central conidiation pathway. The results are relevant to better understand fungal adaptation in PAH-polluted environments, to select suitable fungal strains able to tolerate, grow and degrade high amounts of PAHs and to develop and implement adequate strategies for the remediation of contaminated soils.

\section{Acknowledgments}

This work was supported by the Consejo Nacional de Ciencia y Tecnología (CONACYT) project CB2008105643, the Instituto Politécnico Nacional project SIP20152025 and CONACYT grant 269828.

\section{References}

Abbas HK, Shier WT, Horn BW et al. (2004) Cultural methods for aflatoxin detection. J Toxicol Toxin Rev 23:295-315. 
Adams TH, Yu JH (1998) Coordinate control of secondary metabolite production and asexual sporulation in Aspergillus nidulans. Curr Opin Microbiol 1:674-677.

Brodkorb TS, Legge RL (1992) Enhanced biodegradation of phenanthrene in oil tar-contaminated soils supplemented with Phanerochaete chrysosporium. Appl Environ Microbiol 58:3117-3121.

Carreras-Villasenor N, Sanchez-Arreguin JA, Herrera-Estrella AH (2012) Trichoderma: sensing the environment for survival and dispersal. Microbiology 158:3-16.

Cerniglia CE, Sutherland GR (2010) Degradation of Polycyclic Aromatic Hydrocarbons by Fungi. In Handbook of hydrocarbon and lipid microbiology. Edited by K.N. Timmis. Springer, Berlin; London pp. 2079-2110.

Haritash AK, Kaushik CP (2009) Biodegradation aspects of polycyclic aromatic hydrocarbons (PAHs): a review. J Hazard Mater 169:1-15.

Hinga KR, Batchellor A (2005) Waste Processing and Detoxification. In Ecosystems and human well-being : current state and trends : findings of the Condition and Trends Working Group of the Millennium Ecosystem Assessment. Edited by R.M. Hassan and R. Scholes and N. Ash. Island Press, Washington, DC. pp. xxi, 917 p.

Lugauskas A, Griguceviciene A, Asadauskas S et al. (2008) Selection of micromycetes capable of developing on technical lubricants. Ekologija 54:186-194.

Margesin R, Schinner F (2001) Biodegradation and bioremediation of hydrocarbons in extreme environments. Appl Microbiol Biotechnol 56:650-663.

Marx IJ, van Wyk N, Smit S et al. (2013) Comparative secretome analysis of Trichoderma asperellum S4F8 and Trichoderma reesei Rut $\mathrm{C} 30$ during solid-state fermentation on sugarcane bagasse. Biotech Biofuels 6:172.

Mrozik A, Piotrowska-Seget Z (2010) Bioaugmentation as a strategy for cleaning up of soils contaminated with aromatic compounds. Microbiol Res 165:363-375.

Nyns EJ, Auquiere JP, Wiaux AL (1968) Taxonomic value of the property of fungi to assimilate hydrocarbons. Antonie Van Leeuwenhoek 34:441-457.

Pope JM, Walker LW, Dubro D (1984) On the ordering of $N$-alkane and $N$-alcohol solutes in phospholipid bilayer model membrane systems. Chem Phys Lipids 35:259-277.

Ramos JL, Duque E, Gallegos MT et al. (2002) Mechanisms of solvent tolerance in gram-negative bacteria. Ann Rev Microbiol 56:743-768.
Seo JS, Keum YS, Li QX (2009) Bacterial degradation of aromatic compounds. Int J Environ Res Public Health 6:278309.

Sewall TC, Mims CW, Timberlake WE (1990) Conidium differentiation in Aspergillus nidulans wild-type and wet-white (wetA) mutant strains. Dev Biol 138:499-508.

Shier WT, Lao Y, Steele TW et al. (2005) Yellow pigments used in rapid identification of aflatoxin-producing Aspergillus strains are anthraquinones associated with the aflatoxin biosynthetic pathway. Bioorg Chem 33:426-438.

Sikkema J, de Bont JA, Poolman B (1995) Mechanisms of membrane toxicity of hydrocarbons. Microbiol Rev 59:201-222.

Tabak HH, Lazorchak JM, Lei L et al. (2003) Studies on bioremediation of polycyclic aromatic hydrocarbon-contaminated sediments: bioavailability, biodegradability, and toxicity issues. Environ Toxicol Chem 22:473-482.

Tao L, Yu JH (2011) AbaA and WetA govern distinct stages of Aspergillus fumigatus development. Microbiology 157:313-326.

US-EPA (2008) Polycyclic Aromatic Hydrocarbons (PAHs) [online]. Available from http://www.epa.gov/wastes/hazard/wastemin/minimize/factshts/pahs.pdf [accessed March 2013].

Vasquez A (2010) Estudio de la expresión de un gen suicida en Aspergillus niger para su aplicación en sistemas de biorremediación. M.Sc. Thesis, Instituto Politécnico Nacional, Tlaxcala, México.

Wunder T, Kremer S, Sterner O et al. (1994) Metabolism of the polycyclic aromatic hydrocarbon pyrene by Aspergillus niger SK 9317. Appl Microbiol Biotechnol 42:636-641.

$\mathrm{Yu}$ JH, Butchko RA, Fernandes M et al. (1996) Conservation of structure and function of the aflatoxin regulatory gene aflR from Aspergillus nidulans and A. flavus. Curr Genet 29:549-555.

Zafra G, Absalón AE, Cuevas MC et al. (2014) Isolation and Selection of a Highly Tolerant Microbial Consortium with Potential for PAH Biodegradation from Heavy Crude OilContaminated Soils. Water Air Soil Poll 225:1826.

Zajic JE, Kuehn HH (1962) Biosynthesis of yellow pigments by Aspergillus niger. Mycopathol Mycol Appl 17:149-158.

Associate Editor: Fernando Dini Andreote

All the content of the journal, except where otherwise noted, is licensed under a Creative Commons License CC BY-NC. 